\title{
Biodegradable Plates Versus Titanium Mini-Plates for Fixation of Metacarpal and Phalangeal Fractures
}

\author{
KHALED M. HASSAN, M.D.; AHMED M. MOHAMED, M.D. and HESHAM A. EISSA, M.B.B.Ch., M.S. \\ The Department of Plastic and Reconstructive Surgery, Faculty of Medicine, Minia University, Egypt
}

\begin{abstract}
Background: Metacarpal and phalangeal bones are prone to injury in daily work and life and hand fractures account for about $1.5 \%$ of all emergency room visits. Problems associated with those fractures relate to shortening, rotation, and dorsal apex angulation. If closed methods of treatment fail to achieve or maintain reduction, surgery could be used. Oblique and spiral fractures are prone to mal-rotation so operative fixation could be necessary. Commonly used surgical techniques are Kirschner-wire, miniplate, and screw fixations. Biodegradable materials such as Polyglycolic acid (PGA) and Poly-L-lactic acid (PLA) implants have been widely used for hand fracture fixation including pins, rods, screws and plates.

Patients and Methods: In this study, we compare the results of fixation of metacarpal fractures by titanium metal plates (group A) with the results of biodegradable plates (group B). This study involved twenty patients who presented with metacarpal and phalangeal fractures who presented to the Plastic Surgery Department of Minia University Hospital between March 2016 and December 2016. Surgical procedure was performed under local intravenous or general anaesthesia. We followed cases for 6 months postoperatively.
\end{abstract}

Results: Mean age $=38.9 \pm 14.9$ and $35.7 \pm 13.1$ years old for group A and B respectively. 13 patients were males and 7 were female. Operative time in group A was $55 \pm 19.4$ minutes while in group B, it was $84.5 \pm 21.2$ minutes. In group A, total range of motion was $234 \pm 15.05$ degrees while in group $\mathrm{B}$, it was $133 \pm 17.02$ degrees as measured by goniometer. In group A, time for union was $7.5 \pm 1.7$ weeks while in group B, unfortunately no union occurred. In group A, one case (10\% of cases) was complicated with delayed union and another case of infection (10\% of cases), while in group B all cases were complicated with non-union and fracture displacement which forced us to replace with K-wire fixation.

Conclusion: In this series of metacarpal and phalangeal fractures treated with titanium or biodegradable plates and screws, titanium plates (group A) showed more favorable outcomes. The stable bony construct achievable by using titanium plates and screws (group A) is the key to good functional results compared with the bad results using biodegradable plates and screws (group B). Further studies are required.

Disclosure: The authors have no financial interest to declare in relation to the content of this article.

Key Words: Biodegradable plates - Titanium mini-plates Fractures - Metacarpal-Phalangeal.

\section{INTRODUCTION}

Hand fractures are common and represent about $1.5 \%$ of all emergency room visits and $40 \%$ of upper extremity fractures [1]. The metacarpal and phalangeal fractures can be further sub-classified as transverse, oblique, spiral, or comminuted based on the fracture geometry. Stepping on hand or ball shock, as examples of direct trauma, mostly causes transverse and comminuted fracture, whereas sprain injuries like falling on the outstretched arm causes spiral and oblique fracture [2].

Problems associated with metacarpal and phalangeal fractures relate to shortening, rotation, and dorsal apex angulation. Minor rotational deformities can cause the fingers to overlap when the hand is made into a fist (scissoring). Rotational abnormalities are best judged clinically by comparing the injured and uninjured digits through a full range of motion (ROM). With flexion, each digit should point toward the scaphoid tuberosity. The plane of the nail should be similar between the injured digit and the contralateral corresponding finger when evaluated in an intrinsic plus position [3].

Most metacarpal and phalangeal fractures are treated conservatively, if closed methods fail to achieve or maintain reduction when there is angulation, rotation or shortness because of the location, surgery could be used [2].

The most effective method for fixation of metacarpal and phalangeal fractures has not been established. Commonly used surgical techniques are Kirschner-wire, miniplate, and screw fixations [4].

Mini-fragment screws and plates, when used in properly selected cases, can provide rigid fixation, allowing early mobilization of joints and hence good functional results while avoiding prob- 
lems associated with protruding Kirschner-wires and immobilization [5]. However, the complication rates of metallic implants are high and include nonunion, delayed union, stiffness, plate palpation, infection, and tendon rupture. In addition, metal plate-screws might lead to destruction and osteoporosis in the surrounding bone tissue and a second operation may be needed to remove metals after the bone has healed. Therefore, bio-absorbable implants have been introduced to reduce these problems [6].

The first generation bio-absorbable implants showed a high complication rate due to weak mechanical properties and rapid degradation. This led to the development of stronger devices with improved durability [6]. The first study on the use of biodegradable implants was published in 1966 by Kulkarni et al., who studied the biocompatibility of poly-L-lactic (PLLA) in animals. The material proved to be non-toxic and gradually degraded [7]. Bioabsorbable fracture fixation implants have been considered as an effective fixation system with several advantages over metallic fixation, including radiolucency, no corrosion, no accumulation of metal in tissues, less pain and reduced stressshielding since the implants bear less load initially and gradually transfer the load as they degrade [6]. These devices are most often manufactured from polylactides (polylactic acid, PLA), polyglycolides (polyglycolic acid, PGA) and their co-polymer compositions as they are highly resorbable [8]. A resorbable implant should be free of toxic and mutagenic effects. Nonetheless, there are some problems related to the use of these implants, such as an inflammatory response, rapid loss of initial implant strength, higher refracture rates, inadequate stiffness of the implants, and weakness in comparison to metallic implants [9].

\section{PATIENTS AND METHODS}

Study design: This is a prospective randomized clinical study.

The study was conducted in the Plastic Surgery Department of Minia University Hospital from March 2016 to December 2016. The study involved twenty patients who presented with metacarpal and phalangeal fractures. We had the approval of the Faculty Ethics Committee to conduct the study.

\section{Radiological assessment:}

Digital plain X-rays (standard P-A, lateral views). Oblique views may be required in some cases.

\section{Patients classified into 2 groups:}

Group A: Hand fractures that will be managed by open reduction internal fixation by Titanium mini plates and screws. This group included 10 patients their age range from 26 to 69 years old.

Group B: Hand fractures that will be managed by open reduction internal fixation by biodegradable mini plates and screws, this group included 10 patients their age range from 21 to 65 years old.

\section{Operative technique:}

Position: Supine position with the arm extended over radio-lucent arm piece.

Anesthesia: Most cases were operated on using local intravenous anesthesia (Lidocaine 2\%) with double level pneumatic tourniquet after sleeve application to exsanguinate the limb. Sedation was used for few cases as they were anxious. General anesthesia was used in 2 female cases.

Approach and Incision: A direct incision made on the radial border of the first and second metacarpals and ulnar border of the fifth metacarpal. The third and fourth metacarpals were exposed through a dorsal longitudinal incision between these bones. Phalanges were exposed through dorsal midline or dorso-lateral skin incision. Deep dissection was done either through tendon sparing or through tendon splitting.

Tendon splitting (Fig. 1): Tendon splitting is done in midline. Periosteal elevation is done gently by dissector. Exposure of the fracture and fixation is performed either by using titanium or biodegradable systems. Gentle dissection and closure of each layer after fixation of the fracture is important not to affect gliding mechanism of the extensor apparatus.

In tendon sparring: Fine dissection to expose extensor tendon that is retracted either radially or ulnar followed by periosteal elevation, fracture fixation and closure in an anatomical manner.

Titanium mini plates: Contoured miniature $2.0 \mathrm{~mm}$ plates were used for unstable transverse or short oblique diaphyseal fractures. T or L condylar plate was used for metacarpal head or neck fractures. $1.6 \mathrm{~mm}$ drill bit was used to make holes.

Titanium mini screws: Bicortical Titanim miniscrews was used with screw head diameter $3 \mathrm{~mm}$. Screw threads diameter is $2 \mathrm{~mm}$. Length of screw is $9 \mathrm{~mm}$ for phalanges and $11 \mathrm{~mm}$ for metacarpals. 
Biodegradable implants: PGA plates and screws (KLS Martin, Gebruder Martin GmbH \& Co. KG, Germany) were used in all cases of group B. After reduction of the fracture, the absorbable plate was put in warm water and adopted over the fracture site. Screw holes were created by an appropriate drill bit. The screws were then sonic inserted inside the holes made previously (Fig. 4).

A volar slab was applied postoperatively with the metacarpo-phalangeal joints flexed at $70^{\circ}$ and the inter-phalangeal joints at $0^{\circ}$. All patients were sent for post-operative radiographs. The slab was left for 2 weeks until suture removal. Minimal loadbearing was delayed for another 2 weeks.

Early postoperative care: A well-padded dressing was applied with limb elevation in broad arm sling. Patients were encouraged to do early active range of motion as patient can tolerate pain and under cover of physiotherapist. Intravenous antibiotics were used for 48 hours followed by short course of oral antibiotics.

Late postoperative care (Fig. 2): The patients were routinely evaluated in our outpatient hand clinic every week for a month and monthly for six months. All patients were followed-up to radiographic fracture union or established nonunion. The fracture was considered to be united when the patient had a painless active range of motion, haziness of the fracture line or some time callus bridge in antero-posterior and lateral view. During the final follow-up visit, all patients were functionally evaluated for the total active range of motion. (TROM) which is defined as the total ROM achieved when all three joints meta-carpophalangeal (MCP), proximal inter-phalangeal (PIP) and distal inter-phalangeal (DIP) of a digit are actively flexed or extended simultaneously, minus any extension deficit at any of the three joints. ROM is recorded using a goniometer. Percentage of active range of motion $(\mathrm{AROM})=\mathrm{TROM} / 260$ $x$ 100. Grades of TRAM according to the American society for surgery of the hand (ASSH):

- Excellent: $>85 \%$.

- Good: $75-85 \%$.

- Fair: $65-75 \%$.

- Poor: $<65 \%$.

Statistical analysis: Data analysis done by using SPSS statistical package version 20. For qualitative data, number $(\mathrm{N})$ and percentage (\%). For quantitative data, mean $(\mathrm{X} \sim)$ and standard deviation (SD). Kolmogorov-Smirnov test was used for normality testing. Normally distributed data (parametric) of the two study groups were analyzed using independent sample $(t)$ test. Chi-square test $\left(\mathrm{X}^{2}\right)$ for analysis of qualitative data. Probability cutoff point was 0.05 .
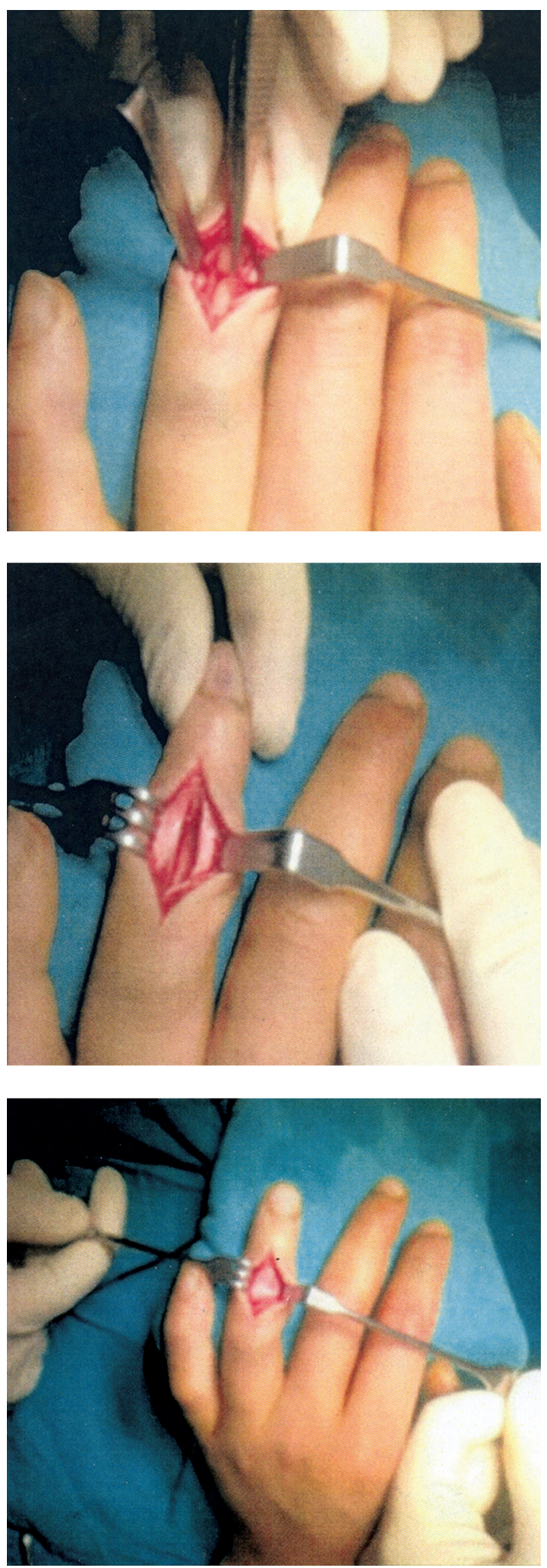

Fig. (1): Dorsal mid line incision, tendon splitting, periosteal elevation. 


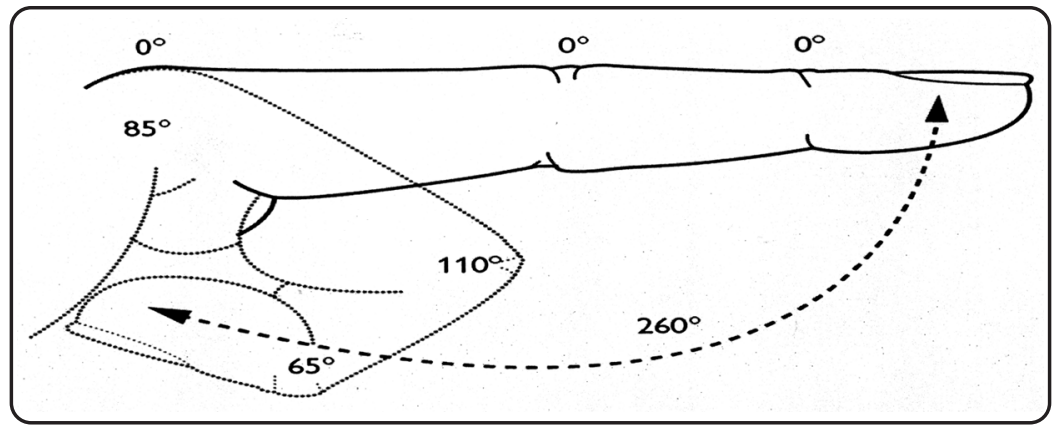

\begin{tabular}{lcc}
\hline \multicolumn{3}{c}{ Normal } \\
\hline Active & Flexion & Extension lag \\
\hline MCP & $85^{\circ}$ & $0^{\circ}$ \\
DIP & $110^{\circ}$ & $0^{\circ}$ \\
DIP & $65^{\circ}$ & $0^{\circ}$ \\
\hline Total & $260^{\circ}$ & $0^{\circ}$ \\
Total active motion (TAM) $260^{\circ}-0^{\circ}=260^{\circ}$ \\
\hline \multicolumn{2}{l}{ Total active motion of the finger. }
\end{tabular}

Fig. (2): Total active range of motion (TARM).

Fig. (3): 25 years old male with fracture right $2^{\text {nd }}$ metacarpal bone that was managed by ORIF by Titanium plates and screws. (A) Pre-operative X-ray. (B) Post-operative Xray. (C) Follow-up photo and $\mathrm{X}$-ray 6 months later note excellent results and full range of movement.
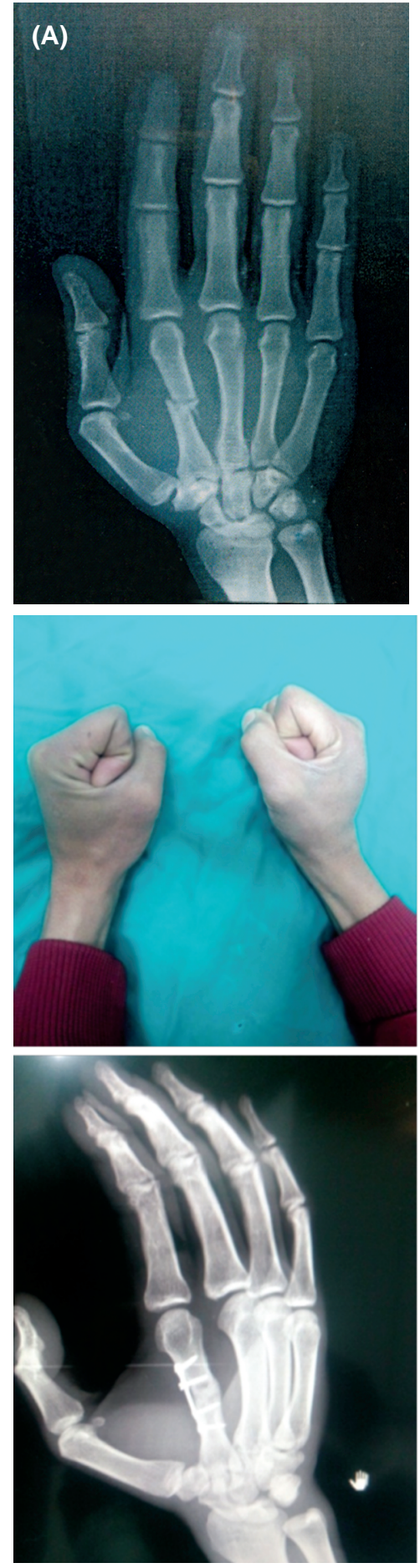

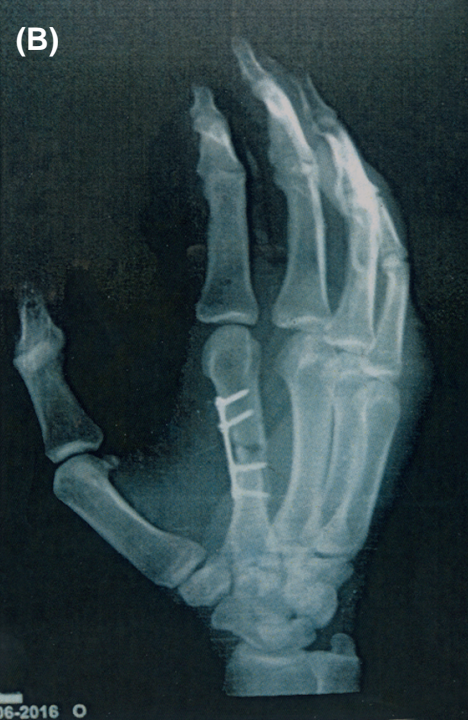

(C)
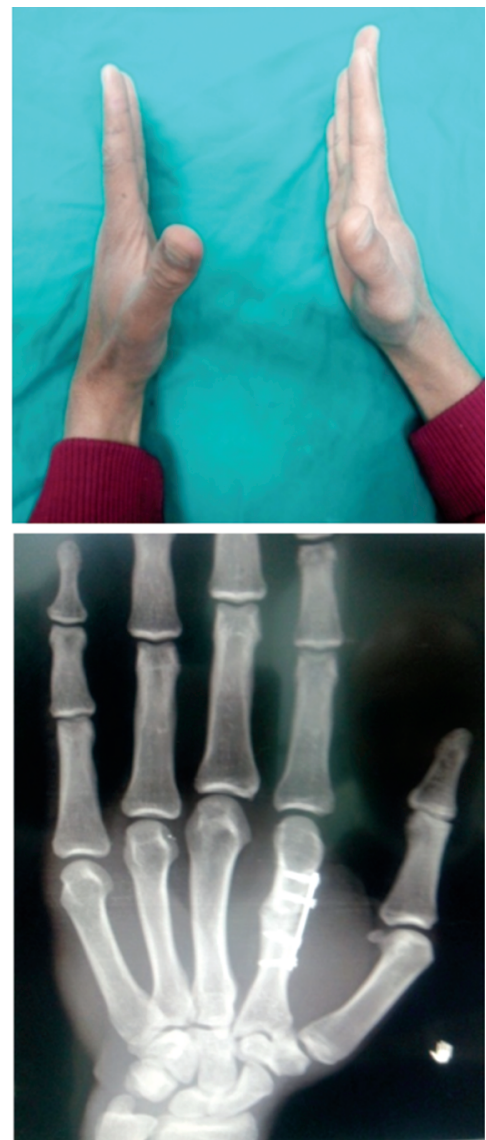
(A)

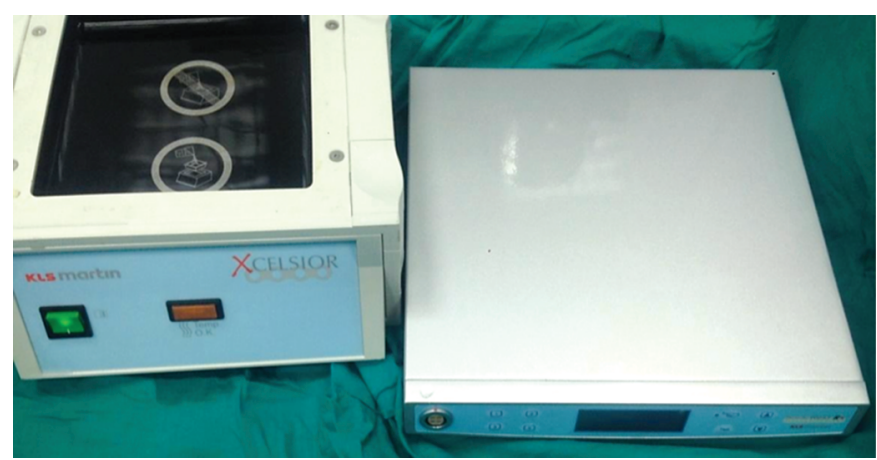

(B)

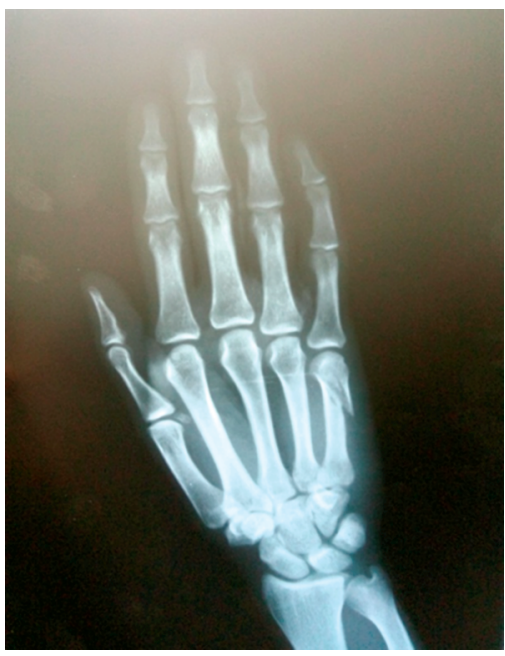

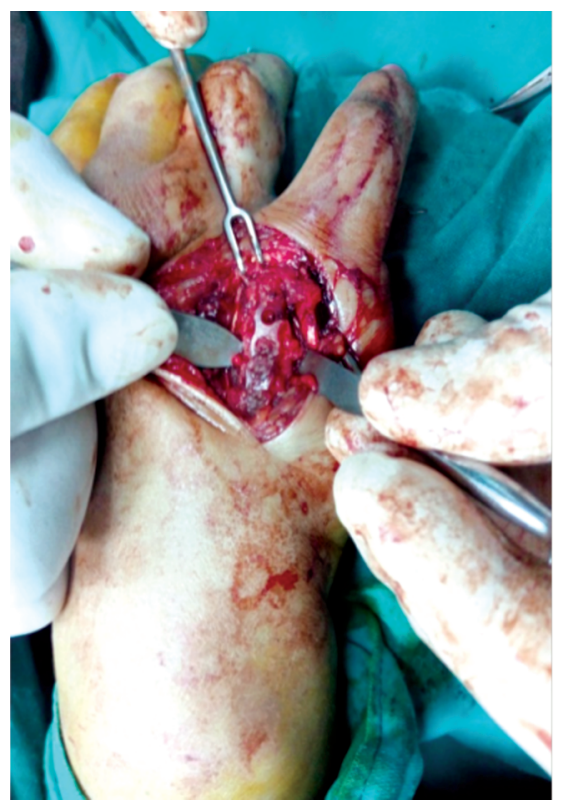

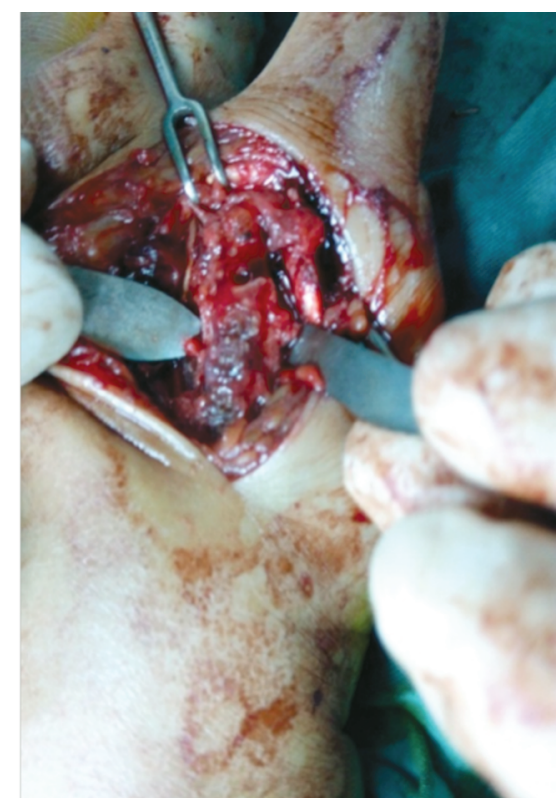

(C)

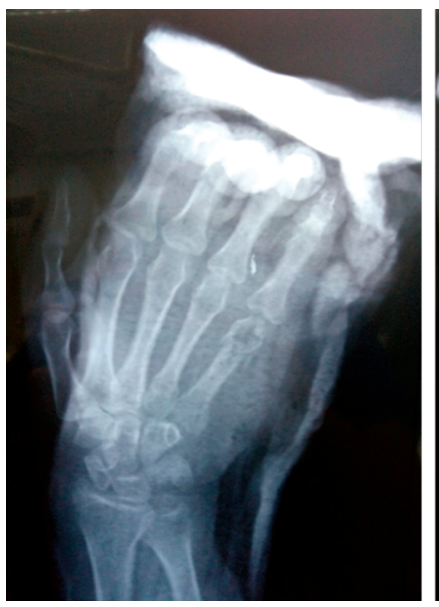

(D)

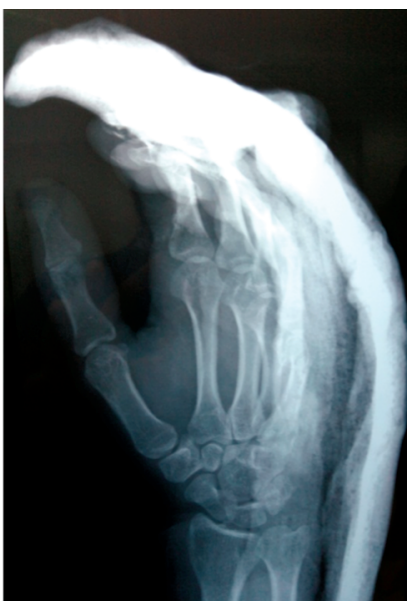

D)
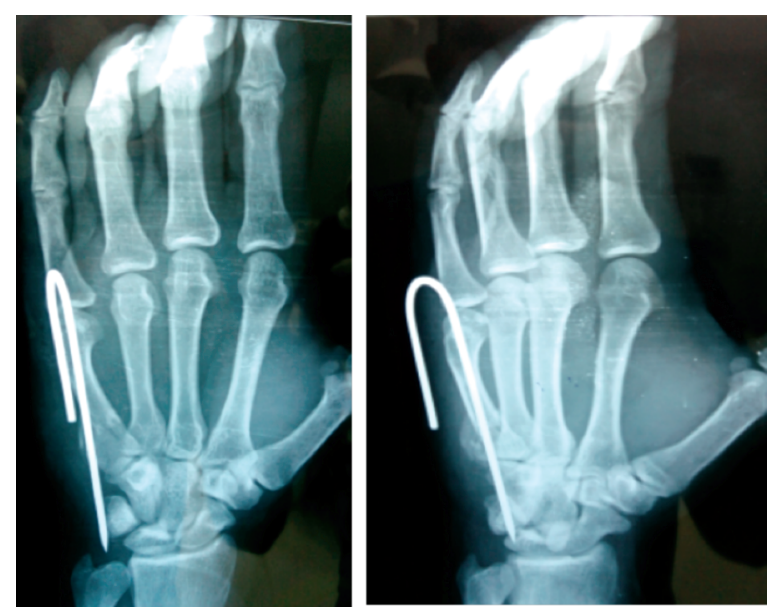

(E)

Fig. (4): 31 years old female with history of direct blow to the hand presented with fracture of left $5^{\text {th }}$ metacarpal bone neck managed by ORIF by biodegradable plates and screws. (A) Sonic weld device. (B) Pre-operative X-ray. (C) Intraoperative photo shows plate adaptation. (D) Post-operative x-ray shows good reduction. (E) Revision later by K-wire for the same case due to fracture angulation. 


\section{RESULTS}

We compared 2 groups of hand fractures managed by open reduction and internal fixation using Titanium mini plates and screws in group A and biodegradable mini plates and screws in group $\mathrm{B}$. The study included 20 patients. Age ranged between 21 and 69 years old with mean age $=38.9 \pm 14.9$ and $35.7 \pm 13.1$ years for group $A$ and $B$ respectively. Group A, included 7 male $(70 \%)$ and 3 female patients (30\%) in while group B included 6 males $(60 \%)$ and 4 female (40\%). Right hand was affected in most cases in both group A and B $(70 \%$ of patients) while left hand was affected in 3 patients $(30 \%)$ only.

Mechanism of injury: Was fall on hand in 7 patients (35\%), RTA in 8 patients $(40 \%)$ and direct blow to the hand in 5 patients $(25 \%)$.

Affected ray: In group A, 2nd ray was affected in 3 patients $(30 \%), 3^{\text {rd }}$ ray in 2 patients $(20 \%)$, $4^{\text {th }}$ ray in 2 patients $(20 \%)$ and $5^{\text {th }}$ ray in 3 patients $(30 \%)$ while in group B, first ray was affected in 2 patients $(20 \%), 2^{\text {nd }}$ ray in one patient $(10 \%), 3^{\text {rd }}$ ray in 2 patients (20\%), $4^{\text {th }}$ ray in one patient $(10 \%)$ and 4 patients $(40 \%)$ with $5^{\text {th }}$ ray affection.

Site of fracture: Group A included 7 patients $(70 \%)$ with metacarpal bone fractures and 3 patients $(30 \%)$ with proximal phalanx fracture while group B included 8 patients ( $80 \%$ ) with metacarpal bone fractures and 2 patients $(20 \%)$ with proximal phalanx fracture.

Type of fracture: Oblique fracture (occurred) in most cases (5 patients) $50 \%$ in group A then transverse fracture in 4 patients $(40 \%)$ and only one patient with spiral fracture $(10 \%)$ in group A while in group B oblique fracture occurred in 2 patients $(20 \%)$, transverse fracture in 4 patients (40\%), spiral fracture in 2 patients $(20 \%)$ and comminuted fracture in 2 patients $(20 \%)$.

Operative time: In group A was $55 \pm 19.4 \mathrm{~min}-$ utes while in group $B$, it was $84.5 \pm 21.2$ minutes (Table 1).

Post-operative total range of motion (TROM): In group $\mathrm{A}$, total range of motion was $234 \pm 15.05$ while in group $\mathrm{B}$, it was $133 \pm 17.02$ degree (Table 1).

Reduction of fracture: Group A included 6 patients $(60 \%)$ with anatomic reduction of fracture and 4 patients $(40 \%)$ with satisfactory reduction while group B included 7 patients (70\%) with anatomic reduction and 3 patients $(30 \%)$ with satisfactory reduction (Table 2).
Callus formation: Callus formation was normal in 7 patients (70\%) in group A and abundant in 3 patients $(30 \%)$ while in group B, there were no patients with normal callus formation and all 10 patients had abundant callus formation (Table 2).

Tourniquet time: In group A, tourniquet time was $49 \pm 15.7$ minutes while in group $B$, it was $77.5 \pm 13.5$ minutes.

Tendon sparing vs. tendon splitting: In group A, Tendon sparing was done in 8 patients $(80 \%)$ while tendon splitting was done only in two patients (20\%). In group B tendon sparing was done in 7 patients (70\%) and tendon splitting was done in 3 patients.

Percentage of total range of motion (TROM): in group A, percentage of TROM was $89.6 \pm 6.02 \%$ while in group B, it was $50.7 \pm 6.3 \%$ (Table 2).

Time till union; in group $\mathrm{A}$, time for union = $7.5 \pm 1.7$ weeks while in group $B$, no union occurred.

Complications: In group A, one case (10\% of cases) was complicated with delayed union and another case of infection (10\% of cases), while in group B all cases were complicated with non-union and fracture displacement which forced us to replace with K-wire fixation.

Table (1): Operative time and TROM.

\begin{tabular}{llcl}
\hline & Group A & Group B & \\
& $\mathrm{N}=10$ & $\mathrm{~N}=10$ & $p$-value \\
& Mean \pm SD & Mean \pm SD & \\
\hline Operative time & $55 \pm 19.4$ & $84.5 \pm 21.2$ & 0.005 \\
TROM & $234 \pm 15.05$ & $133 \pm 17.02$ & $<0.001$ \\
\hline
\end{tabular}

Table (2): Fracture reduction, callus formation and percentage of TROM.

\begin{tabular}{llll}
\hline & $\begin{array}{c}\text { Group A } \\
\mathrm{N}=10\end{array}$ & $\begin{array}{c}\text { Group B } \\
\mathrm{N}=10\end{array}$ & $p$-value \\
\hline $\begin{array}{l}\text { Reduction: } \\
\quad \text { Anatomic }\end{array}$ & $6(60 \%)$ & $7(70 \%)$ & 0.639 \\
$\quad$ Satisfactory & $4(40 \%)$ & $3(30 \%)$ & \\
$\begin{array}{l}\text { Callus formation: } \\
\quad \text { Normal }\end{array}$ & $7(70 \%)$ & $0(0 \%)$ & 0.001 \\
$\quad$ Abundant & $3(30 \%)$ & $10(100 \%)$ & \\
Percentage of TROM & $89.6 \pm 6.02$ & $50.7 \pm 6.3$ & $<0.001$ \\
\hline
\end{tabular}

\section{DISCUSSION}

Commonly used surgical techniques for hand fracture internal fixation are Kirschner-wire, miniplate and screws fixations [4]. Biomechanical studies by Mann et al. (1985) showed that Kirschner- 
wire fixation methods produced weaker fixation than did miniature plates and screws. Osteosynthesis using miniature plates and screws produces anatomical reduction of fractures with stabilization that is rigid enough to allow early mobilization of adjacent joints without allowing loss of reduction, thereby preventing stiffness and hence good functional results.

The present study is a prospective randomized clinical study that was carried out on twenty patients presented with metacarpal and phalangeal fractures. It compares the results of fixation of metacarpal fractures using titanium plates and screws with biodegradable plates and screws. The hypothesis of the study is that the classic fixation of hand fractures by metals is not better than the fixation by biodegradable plates. If we can prove this, the newly advocated biodegradable plates' fixation will be an alternative option to metal fixation for the treatment of hand fractures.

Mumtaz et al., retrospective study on forty patients with 42 unstable metacarpal and phalangeal fractures were treated with open reduction and internal fixation using miniature plates and screws over a period of three years. Twenty-nine patients 29 were male and 11 were female. The average age was 28.5 years. There were 21 metacarpal, 17 proximal phalangeal, and 4 middle phalangeal fractures. Mechanism of injury included fall, direct blow and traffic accident. Of 42 fractures, 10 were transverse, 21 were oblique, 3 were spiral, 6 were intra-articular, and 2 were comminuted. All the fractures were closed fractures. They had good results in $87.5 \%$ of cases. Four cases had superficial infection, two patients had deep infection and one patient had residual deformity [10]. In our study, operative time was $50 \pm 15.4$ minutes in group A while in group $\mathrm{B}$, it was $42.5 \pm 7.9$ minutes. The total tourniquet time (for hand fracture fixation) in group A, ranged from 30 to 70 minutes (with mean $49 \pm 15.7$ minutes) while in group $B$, it ranged from 35 to 55 minutes (with mean $41.5 \pm 6.6$ minutes). Safe duration and pressure for tourniquet use remains a controversy. No strict guidelines have been laid down. A safe time limit of 1-3h has been described. Horlocker et al. (2006) have found a strong correlation of nerve injury with prolonged total tourniquet time with an approximate threefold increase in risk of neurological complications for each 30min increase in tourniquet inflation [11]. We achieved hemostasis by elevation and compression for a little while after wound closure, bandaging and tourniquet release. This helped to decrease the operative time by reducing the time used to achieve hemostasis by the usual way.
Gulati et al., published a prospective study on 21 patients with closed ipsilateral multiple metacarpal fractures treated with open reduction and internal fixation using miniature plates and screws. They assessed functional outcome using the Total Active Flexion (TAF) and the Disabilities of the Arm, Shoulder, and Hand (DASH) scoring systems. They found that union rate was $100 \%$ (in comparison with $100 \%$ in group A and $0 \%$ in group B in our study) was achieved. Functional outcome was excellent in $85.71 \%$ (18 of 21) and good in 9\% (2 of 21) of patients. Average DASH score was 8.47 (range 1-26). Five cases of infection (two deep, three superficial) were reported, which subsided with dressings and antibiotics. In the present study, group A (Fig. 3) showed mean TROM 234 \pm 15.05 while in group B, it was $133 \pm 17.02$. In group A, percentage of TROM was $89.6 \pm 6.02 \%$ while in group B, it was $50.7 \pm 6.3 \%$. Functional outcome was good in $80 \%$ of cases as TROM was $230^{\circ}$ or more in 8 cases and 2 cases had fair results as they have total active motion less than $210^{\circ}$ in group A while it was fair $100 \%$ of cases TROM was less than $210^{\circ}$ in group B [12].

The use of poly glycolic acid (PGA) biodegradable plates and screws is now limited, since materials and copolymers with better degradation properties were introduced. Poly lactic acid (PLLA) implants has a low degradation rate because of this, adverse reaction tend to appear late, even 45 years postoperatively. This renders many studies weak regarding the presentation of true adverse reaction rate in procedures where PLLA implants have been used, since the follow-up of these studies is shorter than the complete absorption time of the material. A review of the first clinical trials where PLLA implants were used presents 14 series that were performed from 1990 to 1996 . A wide variety of reaction rates was reported, from no adverse reactions to swelling in $47 \%$ of the patients. Advances in material science, such as self-reinforcement technique and elimination of factors that were considered responsible for reaction (e.g. dyes and older sterilization techniques), have changed PLLA implants' behavior [13].

Enantiomeric isomers of PLA were mixed to develop a material less crystallic and more hydrophilic than PLLA, in order to accelerate the degradation process and avoid late tissue reactions. Kontakis et al, used P (L/D) LA-PGA copolymer screws in anterior cruciate ligament reconstruction procedures. No material-related tissue reactions were reported in the mean follow-up time of 5.2 years in the 28 patients that were included in the study [14]. 
In a retrospective case series study on twelve unstable displaced metacarpal fractures were studied in 10 patients, the fractures were treated with absorbable plates and screws consisting of the aforementioned copolymers and designed to resorb in 2 to 4 years. Fracture healing was uneventful in all cases. Four patients experienced a foreign-body reaction during the second postoperative year and required surgical debridement to remove implant remnants. Histologic examination confirmed the diagnosis of a foreign-body reaction. Two other patients reported a transient local swelling that subsided without treatment [15].

Xiong et al., designed a flexible intramedullary bio-absorbable rod for the treatment of the metacarpal shaft fractures. Five patients with nine shaft fractures of the fourth and fifth metacarpi were treated and followed up with an average of 4.2 months. All patients achieved fracture union with no signs of inflammatory or subcutaneous effusion. There was no shortening, angulatory, or rotatory deformity. There was almost full active extension range of motion (ROM) of the metacarpophalangeal joints while the active flexion ROM of these joints was $80.7 \pm 9.6^{\circ}$. Compared with the contralateral hand, the grip strength of the injured hand was $94.0 \pm 9.6 \%$. X-rays showed that the arch of the second to fifth metacarpal heads was smooth. There were no intramedullary lytic changes and soft tissue swellings [16].

Table (3): Comparison between the present study and study of Xiong et al.

\begin{tabular}{|c|c|c|}
\hline & $\begin{array}{l}\text { Xiong et al. } \\
\text { (2015) }\end{array}$ & $\begin{array}{c}\text { Group B } \\
\text { (present study) }\end{array}$ \\
\hline No. of patients & 5 & 10 \\
\hline Age & $24.1 \pm 2.7$ & $35.7 \pm 13.1$ \\
\hline Mechanism of injury & $\begin{array}{l}\text { Direct blow, } \\
\text { fall on } \\
\text { hand and } \\
\text { motor } \\
\text { accident }\end{array}$ & Same \\
\hline Affected ray & $4^{\text {th }}$ and $5^{\text {th }}$ & All \\
\hline Material of plates used & $\begin{array}{l}\text { Self reinforced } \\
\text { poly L lactide } \\
\text { (SR PLLA) }\end{array}$ & $\begin{array}{l}\text { Poly Glycolic } \\
\text { Acid (PGA) }\end{array}$ \\
\hline $\begin{array}{l}\text { Time from injury to } \\
\text { operation (days) }\end{array}$ & $10.6 \pm 6.9$ & $2.5 \pm 1.5$ \\
\hline Follow-up time (months) & $4.2 \pm 0.8$ & $4.4 \pm 0.5$ \\
\hline Bone healing time (weeks) & $7.6 \pm 0.8$ & Non union \\
\hline Post-operative ROM & $84.4 \pm 8.5$ & $133 \pm 17.02$ \\
\hline
\end{tabular}

The high incidence of non-union in our study may be explained by the use of PGA biodegradable plates and screws. This type of implant was the only available in our hospital and it was used to fix pediatric maxillofacial fractures as well. The cost to these plates was very high. Another factor that may have affected our results is the relatively small number of patients (sample size) that can be considered a limitation to this study.

Stiffness after hand fractures is common and arguably more challenging to treat than other complications such as mal-union, nonunion, and infection. Preventing stiffness is the most prudent strategy and involves early motion on a foundation of adequate fracture stability and optimal pain management. In addition to early motion, good rehabilitation programs include good patient communication, edema control, and desensitization are required. In the event that finger stiffness sets in despite optimal therapy, consideration must be given to tenolysis, removal of implants, and even arthrolysis [17]. In the present study because of short duration of follow up and lack of regular patients attendance for follow up, we couldn't assess the degree of residual stiffness with each fixation method, in order to compare with published results. The higher rate of complications in our study in comparison to the others most probably was due to implant nature (PGA), weak rehabilitation physiotherapy program or lack of regular follow-up.

Pun et al., published a prospective study on 52 unstable fractures in 47 patients treated with miniature screws and plates: $61.5 \%$ were open fractures and $36.5 \%$ comminuted, $40.4 \%$ had significant soft-tissue injury, and there were 16 extensor tendon and 6 flexor tendon injuries. Their overall results were not satisfactory: Only $27.8 \%$ of their patients had good results, $36.1 \%$ fair and $36.1 \%$ poor. They reported several drawbacks with the design of the miniature plates and screws they used. They also suggested that open or comminuted fractures and soft-tissue injuries were poor prognostic factors, which adversely affected their results [18]. The results of our study and other reports suggest that the outcome after metacarpal and phalangeal fractures is greatly affected by soft-tissue and associated injuries, comminution and exposure of the fracture. We used two approaches on our cases, either tendon sparing or tendon splitting. In group A, Tendon sparing was done in 8 patients $(80 \%)$ and tendon splitting was done only in two patients (20\%), while in group B tendon sparing was done in 7 patients (70\%) and tendon splitting was done in 3 patients. Soft tissue dissection and tendon traction with accidently damage to lateral bands of extensor apparatus in tendon splitting may affect TROM, statistical studies revealed no significant variation in the outcome 
as regard TROM in either tendon splitting or tendon sparing. Intra-operative, fracture exposure and reduction and fixation was more easier in tendon splitting in comparison to tendon sparing approach and so we preferred and recommend tendon splitting approach for surgical exposure of phalangeal fractures especially intra-articular variant to allow anatomical reduction and visualization of articular surface through a wide field.

The most common concerns with the use of miniature plates and screws is that the operating trauma of a wider exposure can impair the gliding function of the flexor and extensor tendons, that the soft-tissue volume available for accommodating implants is relatively small, especially in the digits, and that the screws and plates might be too bulky and might interfere with the balance and function of joints and tendons. The current study recommends low profile implant over the other implants to minimize complications. Pun et al., used stainless steel mini-plates with high profile in 69 patients, had poor results TROM $<180^{\circ}, 47 \%$ of phalangeal fractures and $75 \%$ of metacarpal fractures most probably this type of implant affect gliding tendon mechanism and more prominent.

In group A of the present study, the hand is usually bandaged with a soft dressing, and active ROM activities are started the next day under supervision. With this type of fixation, we have been able to mobilize the joint without loss of fracture position while the bone is healing. A slab was used in group $\mathrm{B}$ to support the biodegradable plating system during the healing process.

\section{Conclusion:}

In this series of metacarpal and phalangeal fractures treated with titanium or biodegradable plates and screws, titanium plates (group A) showed more favorable outcomes. The stable bony construct achievable by using titanium plates and screws (group A) is the key to good functional results compared with the unfavorable results using biodegradable plates and screws (group B). Further studies on biodegradable plating system are required possibly by trying an alternative biodegradable system.

\section{REFERENCES}

1- Hammert W.C.: Treatment of nonunion and malunion following hand fractures. Clin. Plast. Surg., 38 (4): 68395, 2011.

2- Aykut S., Öztürk K., Özcan Ç., et al.: Results of surgical treatment in metacarpal shaft fractures using low profile mini plates. Ulus Travma. Acil. Cerrahi. Derg., 21 (4): 279-84, 2015.
3- Bloom J.M. and Hammert W.C.: Evidence-based medicine: Metacarpal fractures. Plast. Reconstr. Surg., 133 (5): 1252-60, 2014.

4- Xu J. and Zhang C.: Mini-plate versus Kirschner wire internal fixation for treatment of metacarpal and phalangeal fractures in Chinese Han population: A meta-analysis. J. Orthop. Surg. Res., 11: 9-24, 2014.

5- Somboon W.: Comparison of miniplate and K-wire in treatment of metacarpal and phalangeal fractures. The Thai Journal of Surger, 30: 5-10, 2009.

6- Choi J.S., Lee J.H., Kim S.M., et al.: Foreign Body Granuloma after Metacarpal Fracture Treatment with Absorbable implants. Arch. Plast. Surg., 42 (4): 505-7, 2015.

7- Kulkarni R.K., Pani K.C., Neuman C., et al.: Polyactic acid for surgical implants. Arch. Surgery, 93: 839-843, 1966.

8- Pistner H., Bend D.R., Mühling J., et al.: Poly (l-lactide): A long-term degradation study in vivo: Part III. Analytical characterization Biomaterials, 14: 291-298, 1993.

9- Böstman O.M. and Pihlajamäki H.K.: Adverse tissue reactions to bioabsorbable fixation devices. Clinical orthopaedics and Related Research, 371: 216-227, 2000.

10- Mumtaz M.U., Farooq M.A. and Rasool A.A.: Unstable metacarpal and phalangeal fractures: treatment by internal fixation using $\mathrm{AO}$ mini-fragment plates and screws. Ulus. Travma. Acil. Cerrahi. Derg., 16 (4): 334-8, 2010.

11- Horlocker T.T., Hebl J.R., Gali B., et al.: Anesthetic, patient, and surgical risk factors for neurologic complications after prolonged total tourniquet time during total knee arthroplasty. Anesth. Analg., 102 (3): 950-5, 2006.

12- Soni A., Gulati A., Bassi J.L., et al.: Outcome of closed ipsilateral metacarpal fractures treated with mini fragment plates and screws: A prospective study. J. Orthop. Traumatol., 13 (1): 29-33, 2012.

13- Böstman O. and Pihlajamäki H.: Clinical biocompatibility of biodegradable orthopaedic implants for internal fixation: A review. Biomaterials, 21 (24): 2615-21, 2000.

14- Kontakis G.M., Pagkalos J.E. and Tosounidis T.I.: Bioabsorbable materials in orthopaedics. Acta. Orthop. Belg., 73: 159-169, 2007.

15- Givissis P.K., Panagiotis K., et al.: Delayed Foreign-Body Reaction To Absorbable Implants In Metacarpal Fracture Treatment. Clinical Orthopaedics and Related Research,. 468 (12): 3377-3383, 2010.

16- Xiong G., Xiao Z. and Guo S.: Surgical Fixation of Fourth and Fifth Metacarpal Shaft Fractures with Flexible Intramedullary Absorbable Rods: Early Clinical Outcomes and Implications. Chin. Med. J. (Engl.), 128 (21): 2851$2855,2015$.

17- Meals C. and Meals R.: Hand fractures: A review of current treatment strategies. J. Hand. Surg. Am., 38 (5): 1021-1031, 2013.

18- Pun W.K., Chow S.P., So Y.C., et al.: Unstable phalangeal fractures: Treatment by A.O. screw and plate fixation. J. Hand. Surg. Am., 16: 113-117, 1991. 